\title{
Olanzapine-Induced Suppression of Cocaine Self-Administration in Rhesus Monkeys
}

\author{
Leonard L Howel|*, ${ }^{*, 2}$, Kristin M Wilcox', Kimberly P Lindsey' and Heather L Kimmel' \\ 'Yerkes National Primate Research Center, Emory University, Atlanta, GA, USA; ${ }^{2}$ Department of Psychiatry and Behavioral Sciences, \\ Emory University, Atlanta, GA, USA
}

\begin{abstract}
The neuropharmacological profile of the atypical antipsychotic, olanzapine, is consistent with a potentially useful medication for cocaine abuse. The present study utilized an i.v. drug self-administration paradigm in nonhuman primates to obtain definitive evidence regarding the effectiveness of olanzapine to modulate the reinforcing effects of cocaine. The effects of olanzapine were compared directly to those of the neuroleptic, haloperidol. Rhesus monkeys $(n=7)$ were trained to self-administer cocaine $(0.03-0.3 \mathrm{mg} / \mathrm{kg} / \mathrm{injection})$ under a second-order, fixed-interval 600-s schedule with fixed ratio 20 components. Experimental sessions comprised five consecutive fixed intervals, each followed by a I-min timeout. In drug-interaction experiments, a single dose of olanzapine $(0.03-0.3 \mathrm{mg} / \mathrm{kg}) \mathrm{or} \mathrm{haloperidol}$ $(0.01-0.03 \mathrm{mg} / \mathrm{kg})$ was administered i.v. $15 \mathrm{~min}$ presession for at least three consecutive sessions. In drug-substitution experiments, different doses of olanzapine $(0.01-0.1 \mathrm{mg} / \mathrm{kg} /$ injection) were substituted for cocaine until responding stabilized. Olanzapine caused doserelated decreases in cocaine self-administration at pretreatment doses that had no overt behavioral effects indicative of sedation. A dose of $0.1 \mathrm{mg} / \mathrm{kg}$ eliminated cocaine self-administration in all subjects. In contrast, doses of haloperidol that suppressed cocaine selfadministration induced marked sedation and catalepsy. Olanzapine failed to maintain self-administration behavior above saline extinction levels over a range of unit doses. In vivo microdialysis experiments in a second group of awake rhesus monkeys $(n=3)$ confirmed previous reports in rodents that olanzapine effectively increases extracellular dopamine in ventral striatum. The dose of olanzapine that markedly suppressed cocaine self-administration behavior increased dopamine to approximately 190\% of control values. Lastly, pretreatment with fluoxetine had no systematic effect on olanzapine-induced increases in striatal dopamine. The results indicate that olanzapine can effectively suppress cocaine self-administration behavior in nonhuman primates at doses that enhance dopamine release but do not maintain drug self-administration.

Neuropsychopharmacology (2006) 3 I, 585-593. doi:I 0. I038/sj.npp. I 300828; published online 27 July 2005
\end{abstract}

Keywords: olanzapine; cocaine; dopamine; drug self-administration; microdialysis; nonhuman primates

\section{INTRODUCTION}

Cocaine abuse remains a significant health concern, yet no effective pharmacotherapy is currently in clinical use. Cocaine blocks the reuptake of monoamines including dopamine, norepinephrine, and serotonin with approximately equal potency (Heikkila and Manzino, 1984; Reith et al, 1986; Kuhar et al, 1991). However, the acute behavioral effects of cocaine in rodents and primates have been linked most closely to increases in dopamine associated with dopamine transporter (DAT) inhibition (Wise, 1984; Ritz et al, 1987; Kleven and Woolverton, 1993; Howell and Wilcox, 2001). The affinities of several cocaine-

\footnotetext{
*Correspondence: Dr LL Howell, Yerkes National Primate Research Center, Emory University, 954 Gatewood Road NE, Atlanta, GA 30329, USA, Tel: + I 404727 7730, Fax: + I 404727 I266,

E-mail: leonard@rmy.emory.edu

Received 12 January 2005; revised 9 May 2005; accepted 7 June 2005 Online publication: 20 June 2005 at http://www.acnp.org/citations/ Npp062005050024/default.pdf
}

like drugs for DAT correlate well with their potencies for supporting self-administration behavior (Ritz et al, 1987; Bergman et al, 1989, Wilcox et al, 1999). In humans, a significant correlation has been observed between DAT occupancy and the intensity of subjective effects produced by intravenous cocaine (Volkow et al, 1997). Conversely, dopamine antagonists can attenuate specific behavioral effects of cocaine in a surmountable manner including its reinforcing effects (De Wit and Wise, 1977; Woolverton, 1986; Hemby et al, 1996). Cocaine affects neurotransmission in various brain dopamine systems leading to a variety of behavioral effects, but the mesolimbic/mesocortical dopamine system appears to be a critical mediator of the reinforcing effects of cocaine (Kuhar et al, 1991; Wise, 1998). Collectively, the results obtained in behavioral studies provide compelling evidence that dopamine plays a major role in the neuropharmacology and addictive properties of cocaine.

Given the obvious importance of dopaminergic mechanisms in the addictive properties of cocaine, the development 
and use of compounds that target dopaminergic systems represents a reasonable approach for the pharmacological treatment of cocaine abuse. The neuropharmacological profile of the atypical antipsychotic, olanzapine, is consistent with a potentially useful medication. Olanzapine is an antagonist with high affinity for dopamine $\mathrm{D}_{1^{-}}, \mathrm{D}_{2^{-}}$, and $\mathrm{D}_{4}$-receptors (Moore et al, 1993; Bymaster et al, 1996, 1997), and it appears to have mesolimbic selectivity (Moore et al, 1993) consistent with other atypical antipsychotics (Hand et al, 1987). Interestingly, olanzapine induces significant elevations in extracellular dopamine in vivo in the prefrontal cortex, striatum, and nucleus accumbens of rats (Li et al, 1998; Zhang et al, 2000; Koch et al, 2004). In behavioral studies, pretreatment with olanzapine produced dose-dependent decreases in cocaine self-administration in rats trained under a simple fixed-ratio schedule of i.v. drug delivery (Meil and Schechter, 1997). Clozapine, another atypical antipsychotic with a pharmacological profile similar to olanzapine (Moore et al, 1994; Bymaster et al, 1996), significantly attenuated the subjective effects of cocaine in human cocaine abusers (Farren et al, 2000). Collectively, these studies suggest a potential therapeutic role for olanzapine in the treatment of cocaine abuse. Moreover, its antipsychotic actions could serve to alleviate stimulant-induced psychotic-like symptoms that are not targeted by other medications currently under development.

The present study determined the effectiveness of olanzapine in suppressing cocaine self-administration behavior maintained by a complex schedule of i.v. drug delivery in rhesus monkeys. The effects of olanzapine were compared directly to those of the neuroleptic, haloperidol, in order to access the potential contribution of motor side effects. In addition, olanzapine was substituted for cocaine in drug self-administration experiments in order to characterize its reinforcing properties in monkeys with a history of cocaine use. The drug-substitution procedure is a well-validated predictor of abuse liability in humans. Lastly, the neurochemical effects of olanzapine on extracellular dopamine in the ventral striatum of conscious monkeys were determined with in vivo microdialysis techniques. Given the recent clinical interest in potential interactions between selective serotonin reuptake inhibitors (SSRIs) and atypical antipsychotics, the effects of coadministration of fluoxetine and olanzapine on extracellular dopamine also were determined. Olanzapine suppressed cocaine selfadministration at a dose that enhanced dopamine release, but did not exhibit abuse liability or overt motor side effects. Moreover, pretreatment with fluoxetine had no systematic effect on olanzapine-induced increases in extracellular dopamine.

\section{MATERIALS AND METHODS}

\section{General Methods}

Subjects. Six female and four male adult rhesus monkeys (Macaca mulatta) weighing $7.5-13.0 \mathrm{~kg}$ were used as subjects. Each subject was housed individually and fed Purina monkey chow, fruits, and vegetables. Water was continuously available. Animal care procedures strictly followed the NIH 'Guide for the Care and Use of Laboratory
Animals' and were approved by the Institutional Animal Care and Use Committee of Emory University.

\section{Surgery}

Each subject was prepared with a chronic indwelling venous catheter under sterile surgical conditions using a technique described previously (Wilcox et al, 2002). Preoperative antibiotics (Rocephin, $25 \mathrm{mg} / \mathrm{kg}$ or Cefazolin, $25 \mathrm{mg} / \mathrm{kg}$ ) were given on the day of surgery to help prevent infection. A silicone catheter $(0.65 \mathrm{~mm}$ ID, $1.75 \mathrm{~mm}$ OD; Access Technologies, Skokie, IL) was implanted under a combination of Telazol $(4.0 \mathrm{mg} / \mathrm{kg})$ and isoflurane anesthesia using aseptic techniques. The proximal end of the catheter terminated in the vena cava above the right atrium, and the distal end was routed under the skin and attached to a subcutaneous vascular access port (Access Technologies, Skokie, IL) located in the center of the lower back. After surgery, the subject was returned to its home cage and received Banamine $(1.0 \mathrm{mg} / \mathrm{kg})$ every $6 \mathrm{~h}$ for $24 \mathrm{~h}$ postoperatively to reduce pain and discomfort associated with surgery. Catheters were flushed daily with $100 \mathrm{U} / \mathrm{ml}$ heparinized saline to maintain patency. In experiments involving in vivo microdialysis, guide cannulae were implanted bilaterally into the caudate nucleus under sterile conditions. The positioning of the guide cannulae allowed for targeting of the ventral striatum corresponding to the nucleus accumbens. Preoperative antibiotics (Rocephin, $25 \mathrm{mg} / \mathrm{kg}$ ) were given on the day of surgery to help prevent infection. The animals were sedated with Telazol $(4.0 \mathrm{mg} / \mathrm{kg})$ and maintained on isoflurane anesthesia during the surgery. The subjects were positioned in a stereotaxic frame, and coordinates derived from MRI were used for accurate probe placement. A trephine drill was used to make two small burr holes directly above the ventral striatum, and the guide cannulae were inserted to the appropriate depth. Teflon screws attached to the skull were used to anchor cranioplastic cement, and the guide cannulae were enclosed within a small plastic chamber to prevent access by the monkeys. Stainless-steel stylets were placed in the guide cannulae when not in use. Monkeys were allowed to recover from surgery for 2 weeks before initiating microdialysis experiments. All animals received Banamine $(1.0 \mathrm{mg} / \mathrm{kg})$ every 6 for $24 \mathrm{~h}$ postoperatively, or longer if they exhibited signs of discomfort.

\section{Drugs}

Cocaine $\mathrm{HCl}$ (National Institute on Drug Abuse, Rockville, $\mathrm{MD}$ ) and fluoxetine $\mathrm{HCl}$ (Eli Lilly and Company) were dissolved in $0.9 \%$ saline. Drug doses were determined as salts. Olanzapine (Eli Lilly and Company) was dissolved in $0.01 \mathrm{~N} \mathrm{HCl}$ and diluted with distilled water to appropriate concentrations.

\section{BEHAVIORAL METHODS}

During behavioral testing, each monkey was seated in a commercially available primate chair (Primate Products, Redwood City, CA, USA), and a response panel with one lever was mounted on the front of chair. Located above the lever in the center of the response panel were red and white 
stimulus lights. Once the monkey was seated in the chair, a Huber needle (Access Technologies, Skokie, IL) was inserted into the venous access port. The polyvinyl-chloride tubing attached to the Huber needle was connected to a motor-driven syringe (Coulbourn Instruments, Allentown, PA) located outside of the chamber containing the drug solution. A volume of $2.0 \mathrm{ml} /$ infusion was delivered over $7 \mathrm{~s}$. Testing during daily $1-\mathrm{h}$ sessions occurred in a ventilated, sound-attenuating chamber. IBM compatible computers controlled experimental events and recorded data.

Subjects responded for i.v. infusions of cocaine under a second-order schedule of reinforcement, as described previously (Wilcox et al, 2002). The training dose of cocaine was $0.1 \mathrm{mg} / \mathrm{kg} /$ infusion. When the daily session began, the red light on the response panel was illuminated and responding resulted in the delivery of a drug infusion and brief 2-s illumination of the white light. Initially, the fixed ratio (FR) was one (FR 1) and gradually increased to FR 20. Ultimately, a second-order schedule of reinforcement was in effect, with the first FR 20 completed after $10 \mathrm{~min}$ (fixed-interval, FI 10) resulting in a drug infusion. FR 20 components completed within the 10-min FI resulted in illumination of the white light for $2 \mathrm{~s}$. There was a 30-s limited hold for completion of the first FR 20 after the FI 10 had elapsed, and a drug infusion was not delivered if the limited hold expired. Drug infusions were signaled by a change in the lights from red to white for $15 \mathrm{~s}$. Following each drug infusion there was a 1-min timeout during which responding on the lever had no programmed consequences. A total of five infusions could be delivered during a daily session comprising five FI 10-min (FR 20:s) components.

The training sequence remained in effect until responding for cocaine was stable $(<20 \%$ variance in daily response rate over five consecutive days), after which saline was substituted for cocaine until responding decreased to below $30 \%$ of responding for the training dose of cocaine. After saline extinction, the maintenance dose $(0.1 \mathrm{mg} / \mathrm{kg} / \mathrm{infu}-$ sion) of cocaine was reinstated and responding was allowed to stabilize. For pretreatment studies, a given dose of drug was administered i.v. 15 min presession on three consecutive days, typically Tuesday, Wednesday, and Thursday. Vehicle was administered on all days that subjects did not receive a drug pretreatment, and these data contributed to ongoing calculations of baseline stability. Pretreatment doses were administered on two separate occasions in an ascending order. All doses of a particular drug were studied in combination with $0.1 \mathrm{mg} / \mathrm{kg} /$ infusion cocaine first. Subsequently, the maintenance dose of cocaine was changed to $0.3 \mathrm{mg} / \mathrm{kg} /$ infusion, and drug pretreatments were repeated as described above. For drug-substitution studies, each subject was allowed to self-administer several doses of olanzapine in a randomized order. Substitution for each drug dose continued for at least five consecutive sessions, or until responding stabilized $(<20 \%$ variance in daily response rate).

\section{In Vivo Microdialysis Methods}

At the time of testing, each monkey was seated in a commercially available primate chair (Primate Products, Inc., Miami, FL). Daily sessions lasted for approximately $4 \mathrm{~h}$ and were conducted within a ventilated, sound-attenuating chamber. The chair limited movement of the animals and facilitated connections between the implanted probes and appropriate perfusion equipment. A Lexan plate positioned perpendicular to the medial plane of the body, just above shoulder height, ensured that animals could not contact the probe area. A microinjection pump (CMA/102) located outside the chamber continuously delivered artificial cerebrospinal fluid $\left(\mathrm{Na}_{2} \mathrm{HPO}_{4}, 1.0 \mathrm{mM} ; \mathrm{NaCl}, 150 \mathrm{mM}\right.$; $\mathrm{KCl}, 3 \mathrm{mM}$; CaCl, $1.3 \mathrm{mM}$; $\mathrm{MgCl}, 1.0 \mathrm{mM}$; and ascorbic acid, $0.15 \mathrm{mM}$ ) via FEP Teflon tubing to the probe for perfusion at a flow rate of $2.0 \mu \mathrm{l} / \mathrm{min}$.

During a 2-h equilibrium period, animals sat in the chamber, and repeated 10-min samples were obtained. Subsequently, a single dose of cocaine $(0.5 \mathrm{mg} / \mathrm{kg})$, olanzapine $(0.1 \mathrm{mg} / \mathrm{kg})$, fluoxetine $(3.0 \mathrm{mg} / \mathrm{kg})$ or a combination of olanzapine $(0.1 \mathrm{mg} / \mathrm{kg})$ and fluoxetine $(3.0 \mathrm{mg} / \mathrm{kg})$ was administered i.v. to determine drug-induced increases in extracellular dopamine. In drug-combination studies, fluoxetine was administered first, and olanzapine was administered $30 \mathrm{~min}$ later. The order of drug testing was randomized and counterbalanced across treatment conditions, and at least 1 week separated repeated determinations. Samples were collected outside the test chamber at 10-min intervals to ensure that the monkeys were not disturbed during the experiments. Probes were tested in vitro to determine the suitability of probe efficiency and performance before and after in vivo experiments. Microbore HPLC and electrochemical detection quantitated extracellular levels of dopamine according to well-established analytical procedures (Church et al, 1987; Skirboll et al, 1990; Parsons and Justice, 1993).

\section{Data Analysis}

Response rates for individual subjects were analyzed as a function of dose for each drug. Average rates of cocainemaintained responding following pretreatment drugs were compared to rates of cocaine-maintained responding following saline pretreatments using one-way ANOVA. Post hoc comparisons were made using Dunnet's method. Changes in percent basal dopamine were calculated for each drug treatment (increase in extracellular dopamine in the presence of drug/basal level of dopamine) ${ }^{\star} 100 \%$. Mean percent basal dopamine was analyzed as a function of drug and time, and data were derived from individual subjects.

\section{RESULTS}

\section{Drug Self-Administration Studies}

Dose-effect curves for cocaine self-administration generally were characterized as inverted U-shaped functions in individual subjects, although the lowest unit dose $(0.03 \mathrm{mg} / \mathrm{kg} /$ infusion) maintained peak rates of responding in two subjects (RMm-4 and ROu-4) (Figure 1). The highest unit dose $(1.0 \mathrm{mg} / \mathrm{kg} /$ infusion) maintained rates of responding well below peak rates in all subjects. Maintenance doses of cocaine $(0.03-0.3 \mathrm{mg} / \mathrm{kg} /$ infusion) for drug pretreatment studies were selected to encompass doses that maintained high, stable rates of responding above saline extinction levels. Pretreatment with olanzapine $(0.03-0.3 \mathrm{mg} / \mathrm{kg})$ produced significant $(p<0.05)$ reductions in cocaine 


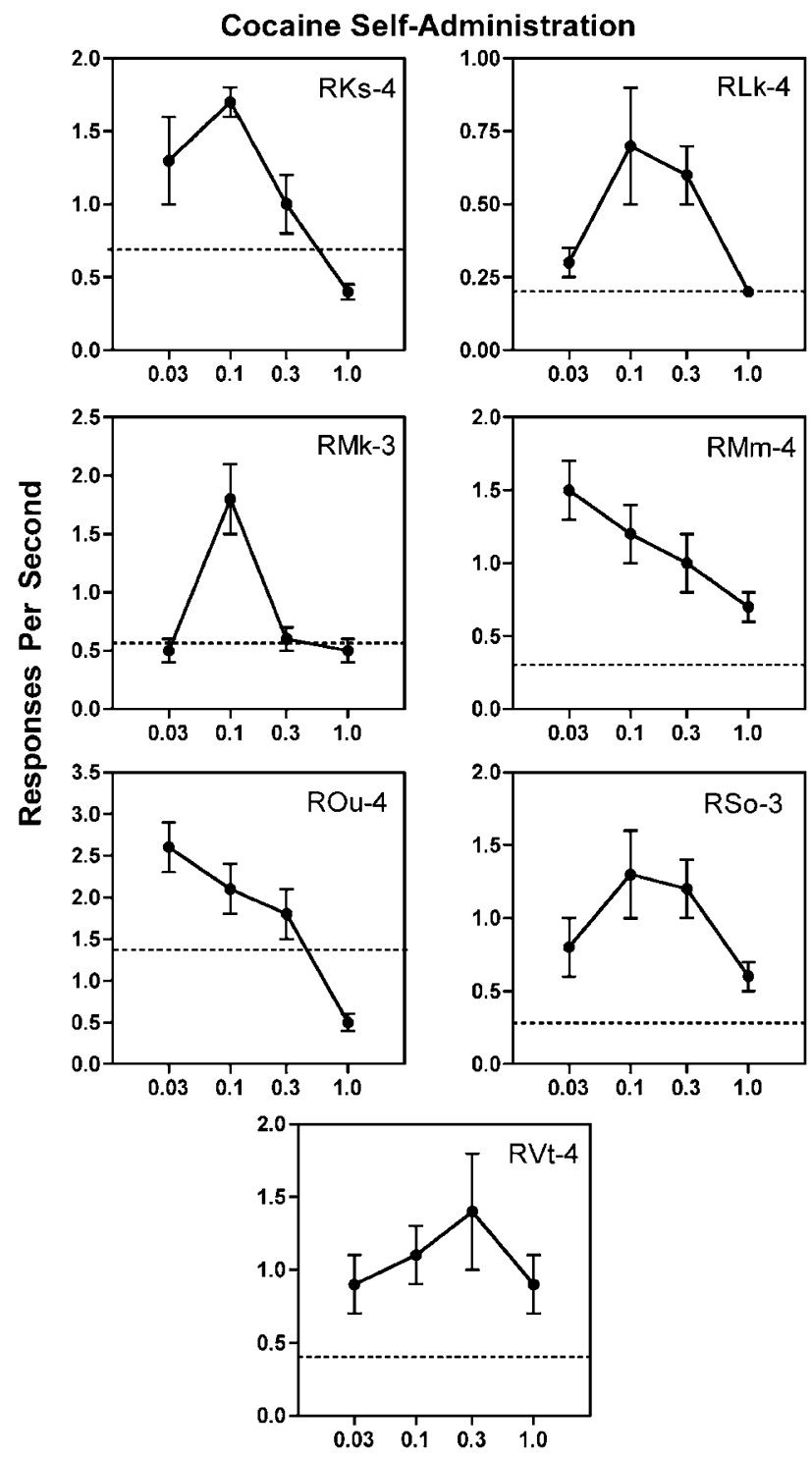

Unit Dose Cocaine ( $\mathrm{mg} / \mathrm{kg} /$ infusion)

Figure I Mean $( \pm S D)$ rates of responding (responses/s) maintained by cocaine self-administration in individual subjects. Data were derived from the last 5 days of each condition that met stability criterion of $<20 \%$ variation. Dashed lines indicate the upper limit for responding during saline extinction.

self-administration in all subjects (Figure 2). There was no change in effectiveness over consecutive 3-day pretreatments, so data were pooled across all pretreatment sessions. Responding was completely eliminated in three of four subjects (RVt-3, RSo-4, and ROu-4) and markedly suppressed in the fourth subject (RMm-4). Olanzapine was more effective in suppressing cocaine self-administration at the higher maintenance dose of cocaine in three of four subjects (RMm-4, RVt-3, and RSo-4) as shown by the leftward position of the olanzapine dose-effect curves. Doses of olanzapine that produced significant reductions in cocaine self-administration had no overt behavioral effects indicative of sedation. Gross observations in the animal home room after test sessions indicated normal behavioral activity.

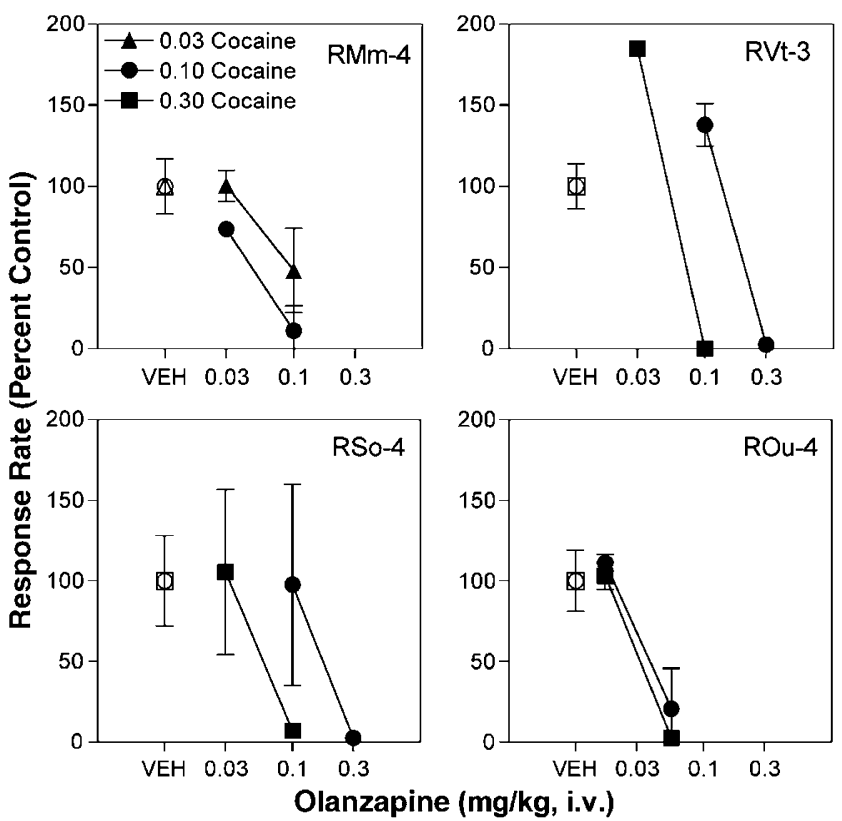

Figure 2 Response rates (percent control) for three maintenance doses of cocaine $(0.03,0.10$, and $0.30 \mathrm{mg} / \mathrm{kg} /$ infusion) after pretreatment with olanzapine as a function of olanzapine dose under a second-order schedule of reinforcement in rhesus monkeys. Each panel represents an individual monkey. Data points over VEH indicate response rates when a vehicle pretreatment was given prior to the cocaine self-administration session.

The effects of olanzapine were compared directly to those of the neuroleptic, haloperidol (Figure 3). Pretreatment with either $0.01 \mathrm{mg} / \mathrm{kg}$ (RMk-4 and RKs-4) or $0.03 \mathrm{mg} / \mathrm{kg}$ (ROu4) produced significant reductions in cocaine self-administration. In contrast to olanzapine pretreatments, the effects of haloperidol were greater on the second and third days of pretreatment compared to the first day of pretreatment. Moreover, doses of haloperidol that suppressed cocaine self-administration caused marked sedation and catalepsy. Gross observations in the animal home room after test sessions indicated pronounced effects on motor behavior. Note that lower doses of haloperidol were ineffective in reducing cocaine self-administration and did not induce observable effects on motor behavior (data not shown). Drug doses shown in Figure 3 represent the lowest doses that suppressed cocaine self-administration in individual subjects.

Olanzapine $(0.01-0.1 \mathrm{mg} / \mathrm{kg} /$ infusion) also was substituted for cocaine in drug self-administration studies in order to characterize its reinforcing effects (Figure 4). When different unit doses of olanzapine were substituted for cocaine for a minimum of 5 consecutive sessions, response rates were similar to or less than those maintained under saline substitution (extinction) conditions. The latter results clearly indicated that olanzapine lacked reinforcing effects.

\section{Microdialysis Studies}

Drug-induced changes in extracellular dopamine in ventral striatum were characterized in awake subjects sitting quietly in a primate chair. Cocaine $(0.5 \mathrm{mg} / \mathrm{kg})$ produced marked elevations in extracellular dopamine to approximately $270 \%$ of baseline values in a group of three subjects (Figure 5). 

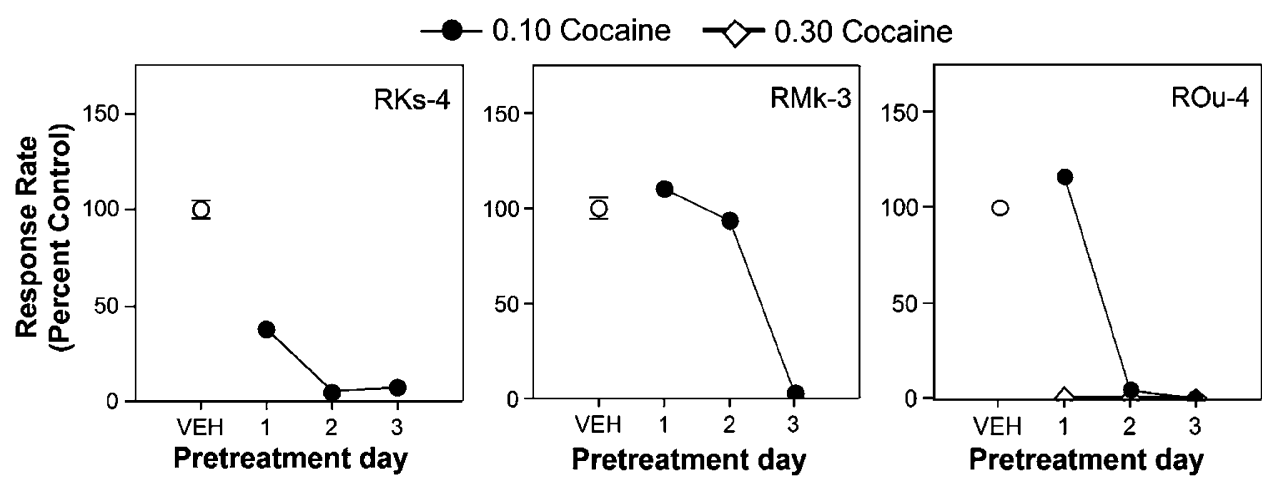

Figure 3 Response rates (percent control) for two maintenance doses of cocaine $(0.10$ and $0.30 \mathrm{mg} / \mathrm{kg} / \mathrm{infusion})$ after pretreatment with haloperidol $(0.01 \mathrm{mg} / \mathrm{kg}, \mathrm{RMk}-3$ and RKs-4; $0.03 \mathrm{mg} / \mathrm{kg}, \mathrm{ROu}-4)$ as a function of pretreatment day under a second-order schedule of reinforcement in rhesus monkeys. Each panel represents an individual monkey. Data points over VEH indicate response rates when a vehicle pretreatment was given prior to the cocaine selfadministration session.
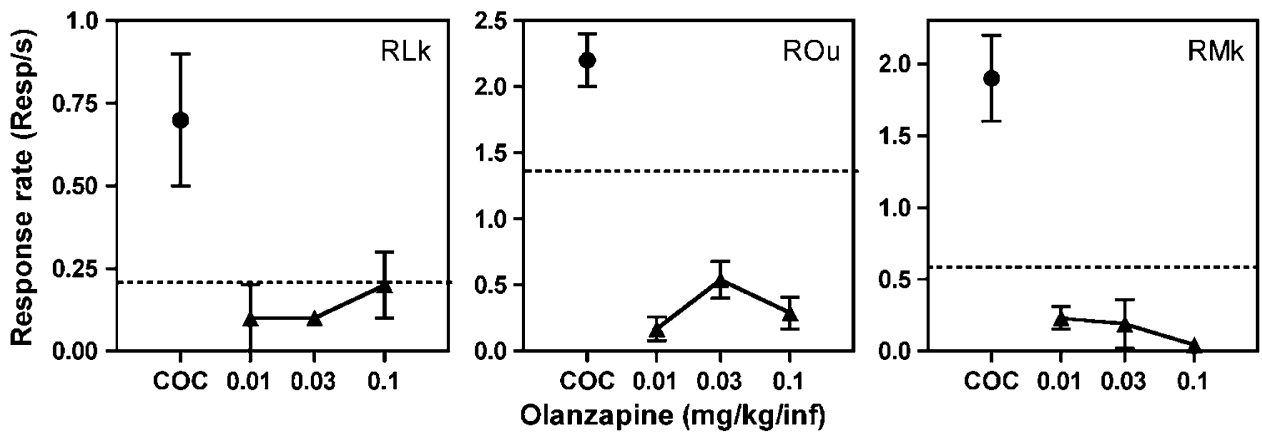

Figure 4 Response rates (responses/s) for olanzapine as a function of dose under a second-order schedule of reinforcement in rhesus monkeys. Each panel represents an individual monkey. Data points over COC indicate response rates for the baseline cocaine dose $(0.10 \mathrm{mg} / \mathrm{kg} / \mathrm{infusion})$. Dashed lines indicate the upper limit of responding during saline extinction. Each data point is the mean of the last five sessions in a condition.

Peak effects were observed $10-30$ min postinjection and returned to baseline within $60-70 \mathrm{~min}$. Compared to cocaine, the effects of olanzapine were less pronounced. Olanzapine $(0.1 \mathrm{mg} / \mathrm{kg})$ increased extracellular dopamine to approximately $190 \%$ of baseline in the same group of three subjects (Figure 5). Moreover, it had a slow onset of action compared to cocaine. Peak effects were observed 60-70 min postinjection and returned to baseline within 110-120 min.

Olanzapine $(0.1 \mathrm{mg} / \mathrm{kg})$ was administered in combination with fluoxetine $(3.0 \mathrm{mg} / \mathrm{kg})$ to characterize their interaction on neurochemistry in vivo in two subjects (Figure 6). The dose of fluoxetine selected was based on published studies reporting interactions with cocaine on behavior in nonhuman primates (Howell and Byrd, 1995). Administration of fluoxetine alone had no effect on extracellular dopamine. Moreover, pretreatment with fluoxetine had no systematic effect on olanzapine-induced increases in extracellular dopamine. There was an attenuation of olanzapine-induced increases in extracellular dopamine in one subject (RBp-3) and an enhancement in the other subject (RJj-7).

\section{DISCUSSION}

This is the first study to characterize the effects of olanzapine on cocaine self-administration behavior and in vivo neurochemistry in nonhuman primates. Olanzapine was effective in suppressing cocaine self-administration behavior maintained by a complex, second-order schedule of i.v. drug delivery in nonhuman primates. Pretreatment with olanzapine completely eliminated cocaine self-administration in three of four subjects, and markedly suppressed responding to less than $10 \%$ of control rates in the fourth subject. Effective doses of olanzapine were within the therapeutic dose range for treatment of psychosis in humans (Brown et al, 1999; Albers et al, 2005). In separate experiments, substitution of olanzapine for cocaine failed to maintain self-administration behavior above saline extinction levels in any subject. Hence, there was no indication in nonhuman primates with a history of cocaine use that olanzapine has abuse liability. A dose of olanzapine that significantly suppressed cocaine self-administration also induced moderate increases in extracellular dopamine in the ventral striatum of conscious subjects. Lastly, the olanzapine-induced increases in dopamine were not influenced systematically by the SSRI, fluoxetine.

Doses of olanzapine that suppressed cocaine self-administration had no overt behavioral effects indicative of sedation as evidenced by gross observations in the animal home room after test sessions. In contrast, reductions in cocaine self-administration induced by the neuroleptic, haloperidol, were accompanied by profound sedation and catalepsy. Moreover, the effects of haloperidol were enhanced over multiple pretreatment days, indicating an accumulation of drug effects on behavior with repeated dosing. It is unclear whether a more sensitive baseline of 
In-Vivo Microdialysis
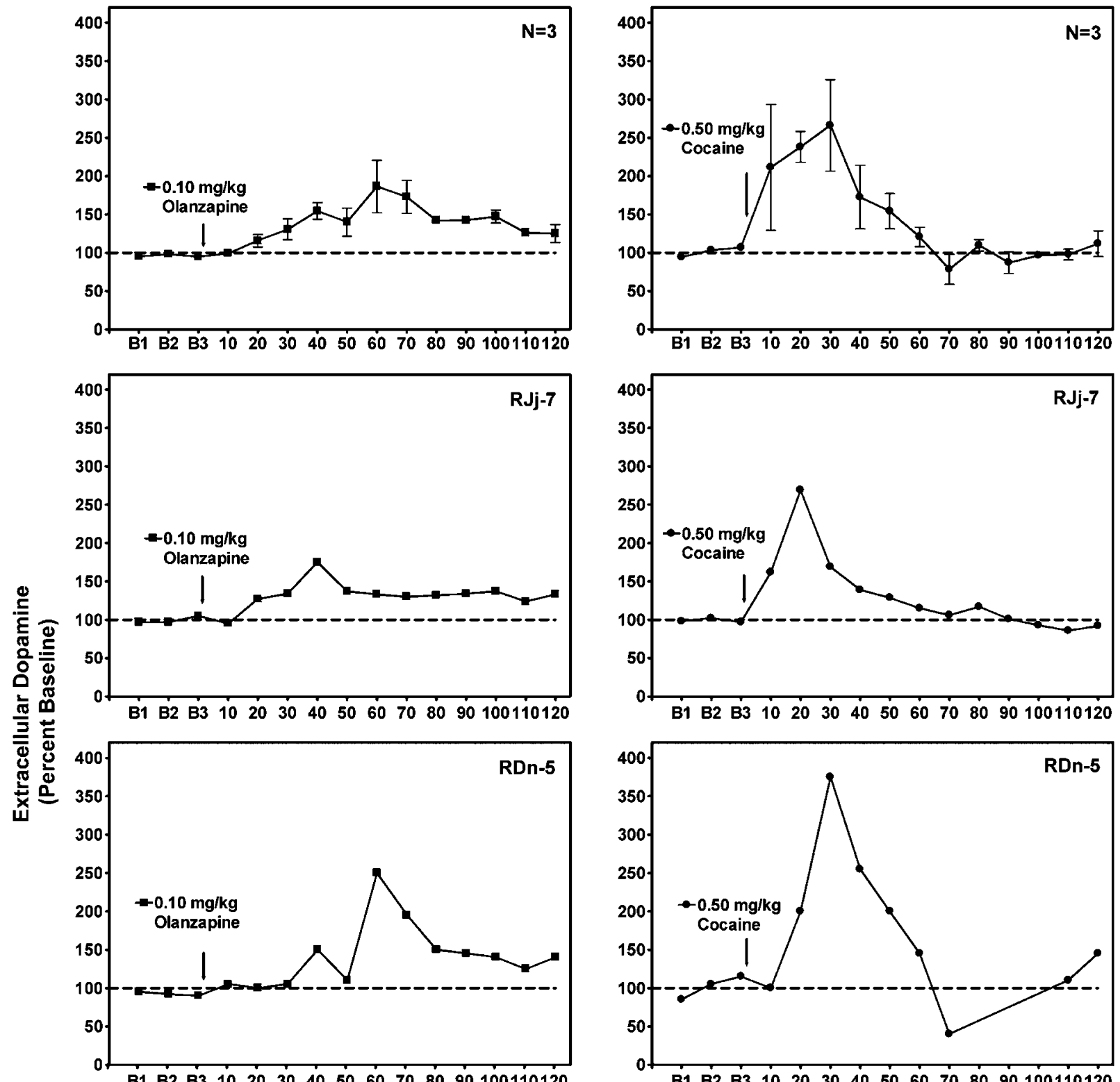

B1 B2 B3 $10203040 \quad 5060708090100110120$
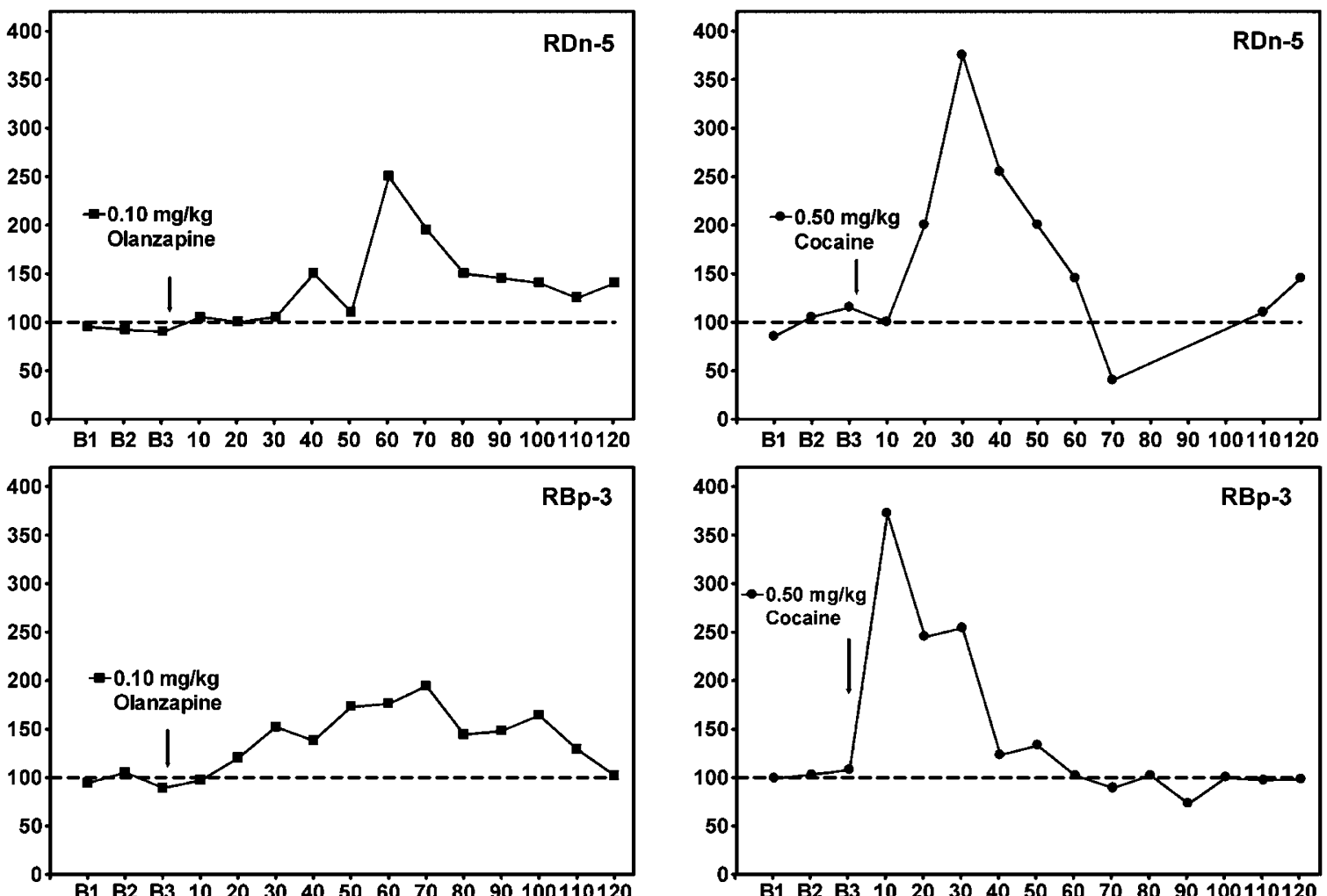

Time (Minutes)

Figure 5 Effects of cocaine $(0.5 \mathrm{mg} / \mathrm{kg})$ or olanzapine $(0.1 \mathrm{mg} / \mathrm{kg})$ on extracellular dopamine levels in ventral striatum of awake rhesus monkeys $(n=3)$ The 10-min sampling intervals indicated began $90 \mathrm{~min}$ after probe insertion. Data points over BLI-3 indicate three 10 -min samples prior to drug injection. 
In-Vivo Microdialysis

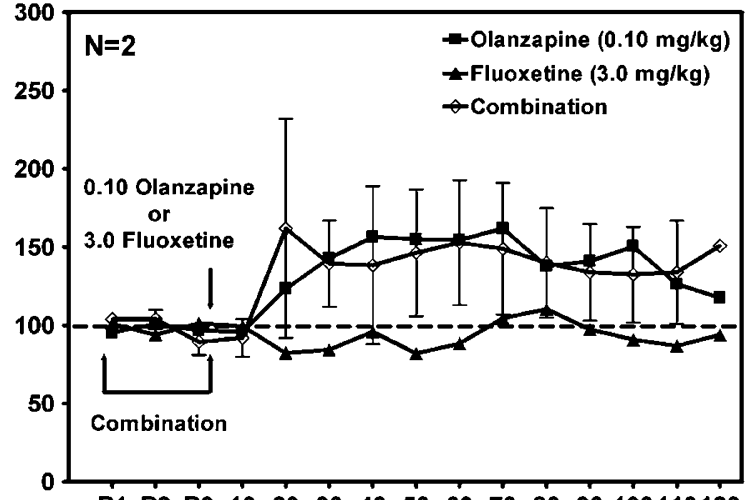

B1 B2 B3 $10 \quad 2030 \quad 405060 \quad 70 \quad 8090100110120$

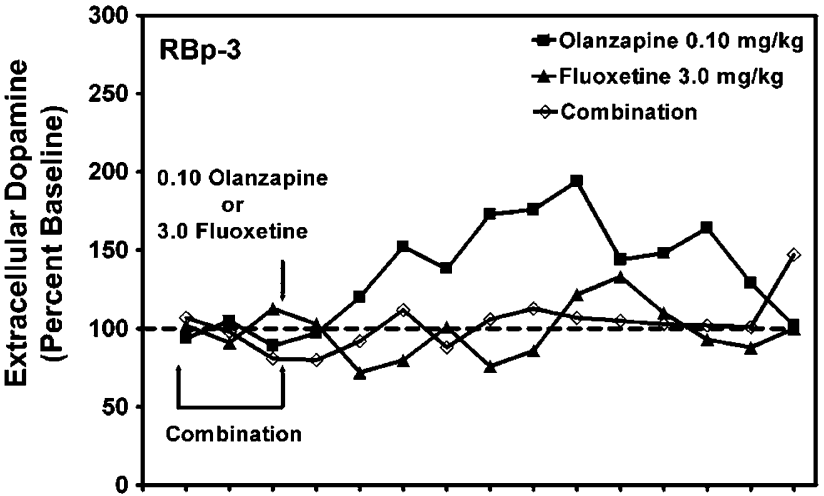

B1 B2 B3 $10 \quad 20 \begin{array}{llllllll}30 & 40 & 60 & 70 & 80 & 90 & 100110120\end{array}$

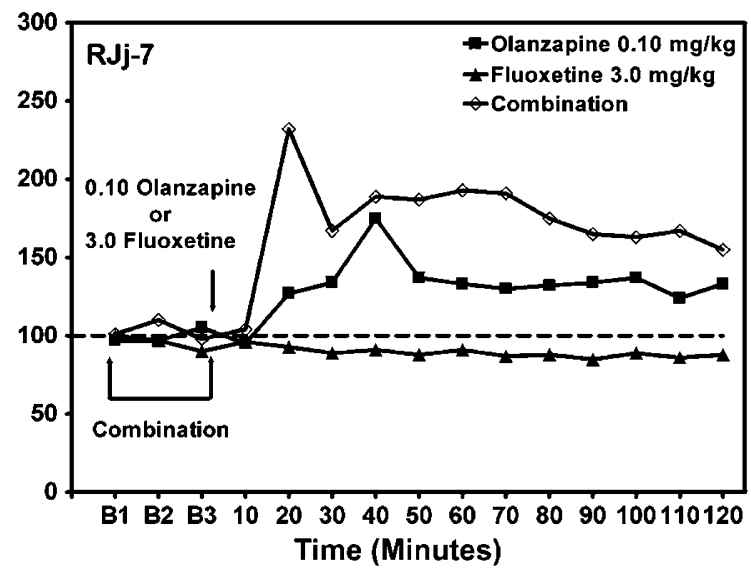

Figure 6 Effects of olanzapine alone $(0.10 \mathrm{mg} / \mathrm{kg})$, fluoxetine alone $(3.0 \mathrm{mg} / \mathrm{kg})$, or the combination on extracellular dopamine levels in ventral striatum of awake rhesus monkeys $(n=2)$. The 10-min sampling intervals indicated began $90 \mathrm{~min}$ after probe insertion. Data points over BLI-3 indicate three 10-min baseline samples prior to drug injection.

operant behavior may have detected nonspecific motor effects induced by olanzapine. Meil and Schechter (1997) reported olanzapine-induced decreases in cocaine selfadministration in rodents, but similar decreases in foodmaintained behavior were observed, suggesting a nonspecific disruption of operant behavior. In the present study, olanzapine was more effective at the higher maintenance dose of cocaine in three of four subjects as shown by the leftward position of the olanzapine dose-effect curves. The latter results are not consistent with a competitive pharmacological antagonism. Also, substitution with olan- zapine for cocaine in self-administration experiments maintained rates of responding that were actually lower than saline extinction conditions in two of three subjects. In the only other study to report the effects of an atypical antipsychotic on cocaine self-administration in nonhuman primates, clozapine was marginally effective in blocking the reinforcing effects of cocaine under a fixed-ratio schedule, and a high dose of clozapine decreased cocaine selfadministration in an apparently nonspecific manner (Vanover et al, 1993). Hence, olanzapine may have produced nonspecific disruptions in operant behavior in the present study that were not evident in gross observations of homecage behavior.

The dose of olanzapine that significantly suppressed cocaine self-administration behavior induced a moderate increase in extracellular dopamine measured in the ventral striatum of conscious subjects. In the primate, the pattern of limbic input to striatum includes areas of the ventral caudate and medial ventral putamen outside that which has traditionally been defined as the nucleus accumbens (Selemon and Goldman-Rakic, 1985; Lynd-Balta and Haber, 1994; Haber and McFarland, 1999). Hence, the region of interest targeted in the present study may be broadly defined as mesolimbic striatum (Bradberry et al, 2000). Compared to a behaviorally relevant dose of cocaine, which corresponded to the total dose administered during daily test sessions, olanzapine-induced increases in dopamine were less pronounced. Olanzapine also had a slower onset and longer duration of action. The results obtained are consistent with those reported previously in rodents showing olanzapine-induced increases in extracellular dopamine in nucleus accumbens (Li et al, 1998). However, it is important to note that olanzapine increases both dopamine and norepinephrine in nucleus accumbens, striatum, and prefrontal cortex (Li et al, 1998). Moreover, olanzapine and other atypical antipsychotics induce greater increases in dopamine and norepinephhrine in the prefrontal cortex compared to subcortical areas in rodents ( $\mathrm{Li}$ et al, 1998; Westerink et al, 1998; Kuroki et al, 1999) and nonhuman primates (Youngren et al, 1999). This preferential augmentation of dopamine release in prefrontal cortex may be an important aspect of their antipsychotic effects (Li et al, 1998; Youngren et al, 1999). Accordingly, the contribution of olanzapine-induced increases in dopamine in ventral striatum to its effects on cocaine selfadministration remains to be defined.

Pretreatment with the SSRI, fluoxetine, had no systematic effect on olanzapine-induced increases in striatal dopamine at a dose of fluoxetine that was approximately one log unit higher than the effective therapeutic dose in the treatment of depression in humans (Wernicke et al, 1989). Similarly, fluoxetine failed to modulate olanzapine-induced increases in dopamine in the striatum or nucleus accumbens of rats (Koch et al, 2004). It should be noted that combined administration of fluoxetine and olanzapine in rats produced sustained increases in dopamine in prefrontal cortex that were significantly greater than either drug alone (Zhang et al, 2000). Hence, interactions between fluoxetine and olanzapine on dopaminergic function may be regionally selective. Recently, there has been major interest in potential interactions between SSRIs and atypical antipsychotics, including olanzapine. Conventional antidepressant 
treatment is ineffective in a significant number of patients with major depression, and when concomitant psychiatric symptoms are present, response outcomes are less favorable. Olanzapine may provide an augmentation strategy for treatment-resistant and psychotic depression as evidenced by recent clinical studies (Thase, 2002; Shelton et al, 2001). Presently, the neurochemical basis underlying the therapeutic effects of fluoxetine/olanzapine combinations is unknown. It is reasonable to speculate that enhanced dopamine release in prefrontal cortex may provide an important neurochemical mechanism (Zhang et al, 2000). However, the present results in conjunction with those reported by Koch et al (2004) suggest that augmented dopamine release in mesolimbic striatum may not contribute to therapeutic effectiveness of fluoxetine/olanzapine combinations.

In summary, olanzapine was effective in suppressing cocaine self-administration behavior in nonhuman primates. Effective doses of olanzapine did not exhibit obvious motor side effects or reinforcing effects indicative of abuse liability. A dose of olanzapine that suppressed cocaine selfadministration in all subjects also induced modest increases in mesolimbic dopamine. Although the results suggest a potential therapeutic role for olanzapine in the treatment of cocaine abuse, placebo-controlled clinical studies in human cocaine users were not encouraging (Kampman et al, 2003). It remains to be determined whether adverse side effects will limit the use of olanzapine in the treatment of cocaine abuse, or whether combination therapy with SSRIs may augment the effectiveness of olanzapine as a cocaine pharmacotherapy.

\section{ACKNOWLEDGEMENTS}

This work was supported by Investigator Initiated Contracts with Eli Lilly and Company, an Independent Scientist Award (K02 DA00517) from the National Institute on Drug Abuse, National Institutes of Health, and Grant RR00165 from the Division of Research Resources, National Institutes of Health. The Yerkes National Primate Research Center is fully accredited by the Association for the Assessment and Accreditation of Laboratory Animal Care International (AAALAC International). We gratefully acknowledge the technical assistance of Dr George Keshelava, Tango Howard, Olga Epstein, Lisa Neidert, and Peggy Plant.

\section{REFERENCES}

Albers LJ, Ozdemir V, Marder SR, Raggi MA, Aravagiri M, Endrenyi L et al (2005). Low-dose fluvoxamine as an adjunct to reduce olanzapine therapeutic dose requirements: a prospective dose-adjusted drug interaction strategy. J Clin Psychopharmacol 25: $170-174$.

Bergman J, Madras BK, Johnson SE, Spealman RD (1989). Effects of cocaine and related drugs in nonhuman primates. III. Selfadministration by squirrel monkeys. J Pharmacol Exp Ther 251: 150-155.

Bradberry CW, Barrett-Larimore RL, Jatlow P, Rubino SR (2000). Impact of self-administered cocaine and cocaine cues on extracellular dopamine in mesolimbic and sensorimotor striatum in rhesus monkeys. J Neurosci 20: 3874-3883.
Brown CS, Markowitz JS, Moore TR, Parker NG (1999). Atypical antipsychotics: Part II: Adverse effects, drug interactions, and costs. Ann Pharmacother 33: 210-217.

Bymaster FP, Calligaro DO, Falcone JF, Marsh RD, Moore NA, Tye NC et al (1996). Radioreceptor binding profile of the atypical antipsychotic olanzapine. Neuropsychopharmacology 14: 87-96.

Bymaster FP, Rasmussen K, Calligaro DO, Nelson DL, DeLapp NW, Wong DT et al (1997). In vitro and in vivo biochemistry of olanzapine: a novel, atypical antipsychotic drug. J Clin Psychiatry 58(Suppl 10): 28-36.

Church WH, Justice Jr JB, Byrd LD (1987). Extracellular dopamine in rat striatum following uptake inhibition by cocaine, nomifensine and benztropine. Eur J Pharmacol 139: 345-348.

De Wit H, Wise RA (1977). Blockade of cocaine reinforcement in rats with the dopamine receptor blocker pimozide, but not with the noradrenergic blockers phentolamine or phenoxybenzamine. Can J Psychol 31: 195-203.

Farren CK, Hameedi FA, Rosen MA, Woods S, Jatlow P, Kosten TR (2000). Significant interaction between clozapine and cocaine in cocaine addicts. Drug Alcohol Depend 59: 153-163.

Haber SN, McFarland NR (1999). The concept of the ventral striatum in nonhuman primates. Ann NY Acad Sci 877: 33-48.

Hand TH, Hu XT, Wang RY (1987). Differential effects of acute clozapine and haloperidol on the activity of ventral tegmental (A10) and nigrostriatal (A9) dopamine neurons. Brain Res 415: 257-269.

Heikkila RE, Manzino L (1984). Behavioral properties of GBR 12909, GBR 13069 and GBR 13098: specific inhibitors of dopamine uptake. Eur J Pharmacol 103: 241-248.

Hemby SE, Smith JE, Dworkin SI (1996). The effects of eticlopride and naltrexone on responding maintained by food, cocaine, heroin and cocaine/heroin combinations in rats. J Pharmacol Exp Ther 277: 1247-1258.

Howell LL, Byrd LD (1995). Serotonergic modulation of the behavioral effects of cocaine in the squirrel monkey. J Pharmacol Exp Ther 275: 1551-1559.

Howell LL, Wilcox KM (2001). The dopamine transporter and cocaine medication development: drug self-administration in nonhuman primates. J Pharmacol Exp Ther 298: 1-6.

Kampman KM, Pettinati H, Lynch KG, Sparkman T, O'Brien CP (2003). A pilot trial of olanzapine for the treatment of cocaine dependence. Drug Alcohol Depend 70: 29-37.

Kleven MS, Woolverton WL (1993). Effects of three monoamine uptake inhibitors on behavior maintained by cocaine or food presentation in rhesus monkeys. Drug Alcohol Depend 31: 149-158.

Koch S, Perry KW, Bymaster FP (2004). Brain region and dose effects of an olanzapine/fluoxetine combination on extracellular monoamine concentrations in the rat. Neuropharmacology 46: 232-242.

Kuhar MJ, Ritz MC, Boja JW (1991). The dopamine hypothesis of the reinforcing properties of cocaine. Trends Neurosci 14: 299-302.

Kuroki T, Meltzer HY, Ichikawa J (1999). Effects of antipsychotic drugs on extracellular dopamine levels in rat medial prefrontal cortex and nucleus accumbens. J Pharmacol Exp Ther 288: 774-781.

Li X-M, Perry KW, Wong DT, Bymaster FP (1998). Olanzapine increases in vivo dopamine and norepinephrine release in rat prefrontal cortex, nucleus accumbens and striatum. Psychopharmacology 136: 153-161.

Lynd-Balta E, Haber SN (1994). The organization of midbrain projections to the ventral striatum in the primate. Neuroscience 59: 609-623.

Meil WM, Schechter MD (1997). Olanzapine attenuates the reinforcing effects of cocaine. Eur J Pharmacol 340: 17-26. 
Moore NA, Calligaro DO, Wong DT, Bymaster F, Tye NC (1993). The pharmacology of olanzapine and other new antipsychotic agents. Curr Opin Invest Drugs 2: 281-293.

Moore NA, Rees G, Sanger G, Tye NC (1994). Effects of olanzapine and other antipsychotic agents on responding maintained by a conflict schedule. Behav Pharmacol 5: 196-202.

Parsons LH, Justice Jr JB (1993). Perfusate serotonin increases extracellular dopamine in the nucleus accumbens as measured by in vivo microdialysis. Brain Res 606: 195-199.

Reith MEA, Meisler BE, Sershen H, Lajtha A (1986). Structural requirements for cocaine congeners to interact with dopamine and serotonin uptake sites in mouse brain and to induce stereotyped behavior. Biochem Pharmacol 35: 1123-1129.

Ritz MC, Lamb RJ, Goldberg SR, Kuhar MJ (1987). Cocaine receptors on dopamine transporters are related to self-administration of cocaine. Science 237: 1219-1223.

Selemon LD, Goldman-Rakic PS (1985). Longitudinal topography and interdigitation of corticostriatal projections in the rhesus monkey. J Neurosci 5: 776-794.

Shelton RC, Tollefson GD, Tohen M, Stahl S, Gannon KS, Jacobs TG et al (2001). A novel augmentation strategy for treating resistant major depression. Am J Psychiatry 158: 131-134.

Skirboll S, Wang J, Mefford I, Hsiao J, Bankiewicz KS (1990). In vivo changes of catecholamines in hemiparkinsonian monkeys measured by microdialysis. Exp Neurol 110: 187-193.

Thase ME (2002). What role do atypical antipsychotic drugs have in treatment-resistant depression? J Clin Psychiatry 63: 95-103.

Vanover KE, Piercey MF, Woolverton WL (1993). Evaluation of the reinforcing and discriminative stimulus effects of cocaine in combination with (+)-AJ76 or clozapine. J Pharmacol Exp Ther 266: 780-789.

Volkow ND, Wang GJ, Fischman MW, Foltin RW, Fowler JS, Abumrad NN et al (1997). Relationship between subjective effects of cocaine and dopamine transporter occupancy. Nature (London) 386: 827-830.

Wernicke JF, Bosomworth JC, Ashbrook E. (1989). Fluoxetine at $20 \mathrm{mg}$ per day: the recommended and therapeutic dose in the treatment of depression. Int Clin Psychopharmacol 4(Suppl 1): 63-67.

Westerink BH, de Boer P, de Vries JB, Kruse CG, Long SK (1998). Antipsychotic drugs induce similar effects on the release of dopamine and noradrenaline in the medial prefrontal cortex of the rat brain. Eur J Pharmacol 361: 27-33.

Wilcox KM, Paul IA, Woolverton WL (1999). Comparison between dopamine transporter affinity and self-administration potency of local anesthetics in rhesus monkeys. Eur J Pharmacol 367: $175-181$.

Wilcox KM, Lindsey KP, Votaw JR, Goodman MM, Martarello L, Carroll FI et al (2002). Self-administration of cocaine and the cocaine analog RTI-113: relationship to dopamine transporter occupancy determined by PET neuroimaging in rhesus monkeys. Synapse 43: 78-85.

Wise RA (1984). Neural mechanisms of the reinforcing action of cocaine. NIDA Res Monogr 50: 15-33.

Wise RA (1998). Drug-activation of brain reward pathways. Drug Alcohol Depend 51: 13-22.

Woolverton WL (1986). Effects of a $\mathrm{D}_{1}$ and a $\mathrm{D}_{2}$ dopamine antagonist on the self-administration of cocaine and piribedil by rhesus monkeys. Pharmacol Biochem Behav 24: 531-535.

Youngren KD, Inglis FM, Pivirotto PJ, Jedema HP, Bradberry CW, Goldman-Rakic PS et al (1999). Clozapine preferentially increases dopamine release in the rhesus monkey prefrontal cortex compared with the caudate nucleus. Neuropsychopharmacology 20: 403-412.

Zhang W, Perry KW, Wong DT, Potts BD, Bao J, Tollefson GD et al (2000). Synergistic effects of olanzapine and other antipsychotic agents in combination with fluoxetine on norepinephrine and dopamine release in rat prefrontal cortex. Neuropsychopharmacology 23: 250-262. 